\title{
THE EFFECTS OF CHANGES IN HYDROGEN ION CONCEN- TRATION ON THE BLOOD FLOW OF MORPHINIZED DOGS
}

\author{
BY TINSLEY RANDOLPH HARRISON, CHARLES P. WILSON \\ AND ALFRED BLALOCK
}

(From the Departments of Medicine, Pathology and Surgery of The Johns Hopkins University)

(Received for publication, May 28, 1925)

\section{INTRODUCTION}

The authors have recently studied the effects of partial respiratory obstruction on the respiration and circulation of the morphinized dog. In a previous communication (Blalock, Harrison and Wilson, 1925), it has been shown that when experimental respiratory obstruction is produced in dogs these animals develop a marked acidosis dependent on carbon dioxide retention and at the same time show an increase of from 40 to 200 per cent in the circulatory minute volume.

The object of the present study was to determine whether an acidosis independent of respiratory obstruction was accompanied by an increased blood flow, and, if this occurred, to observe the effect of the administration of alkali on the circulation in normal dogs and in dogs to which acid had been administered.

\section{METHOD}

The technique, and the objections to the method used are discussed in detail in the former paper (Blalock, Harrison and Wilson, 1925). The procedure, in brief, was as follows:

Dogs were anesthetized with 0.06 gram of morphine, since it has been shown that this drug has relatively slight effect on the blood flow of normal dogs. The oxygen consumpton was determined by a Benedict spirometer, with the graphic recording device. A specimen of blood was drawn from the right ventricle according to the procedure of Barcroft, Boycott, Dunn and Peters (1920). At the same time samples were taken from the carotid and femoral arteries. 
One of the arterial samples was used for $\mathrm{pH}$ determination according to Hawkins' (1923) modification of Cullen's (1922) colorimetric method. In many of the experiments in which acid was injected slight laking of the blood occurred and accurate $\mathrm{pH}$ readings were difficult. Greater accuracy than $\pm \mathrm{pH} 0.03$ is not assumed. However the changes found in $\mathrm{H}$-ion concentration were much greater than the limits of error of the method.

The oxygen and carbon dioxide content of the arterial and venous blood were determined. The circulatory minute volume was calculated from the Fick formula: $\frac{\text { cc. } \mathrm{O}_{2} \text { consumed per minute }}{\text { Amount } \mathrm{O}_{2} \text { taken up in lungs by } 1 \mathrm{cc} \text {. of blood }}=\begin{gathered}\text { Number of cubic centimeters of blood } \\ \text { flowing through lungs per minute }\end{gathered}$

Acid and alkali were injected into the femoral vein. In some experiments $\mathrm{N} / 5 \mathrm{HCl}$ was used, in others $\mathrm{N} / 5, \mathrm{~N} / 2.5$ or $\mathrm{N} / 1$ lactic acid, $\mathrm{N} / 1$ and $2 \mathrm{~N} \mathrm{Na}_{2} \mathrm{CO}_{3}$ were used. The amount of acid or alkali given was varied in different experiments, according to the size of the animal and the degree of change in $\mathrm{pH}$ desired. Fifty to $100 \mathrm{cc}$. were injected in most instances. Some animals received acid alone, some alkali alone, while in a third group both acid and alkali were given. Five to ten minutes after the injection a second series of blood samples was taken. Forty-five to ninety minutes later a third series was withdrawn.

At the conclusion of the experiments the animals were autopsied, and the heart chamber examined. When a puncture in the intraventricular septum was found the experiment was discarded. In this way faulty results such as might have been obtained from mixing arterial and venous blood, were avoided.

\section{RESULTS}

The animals were quiet and remained so throughout the experiments, with one exception (table 7). In some instances the respirations were very rapid whereas in others the breathing was normal or slowed. (It is well known that morphia produces an initial stimulation of the respiration of dogs.) The pulse was always slow at the beginning of the experiments. The animals were not cyanotic. The arterial and venous bloods were normally saturated with oxygen. The $\mathrm{CO}_{2}$ contents were slightly elevated (42 to 54 volumes per cent) and the $\mathrm{H}$-ion concentration slightly depressed (7.21 to 7.31). These are typical morphine effects. The control blood flows were between one 


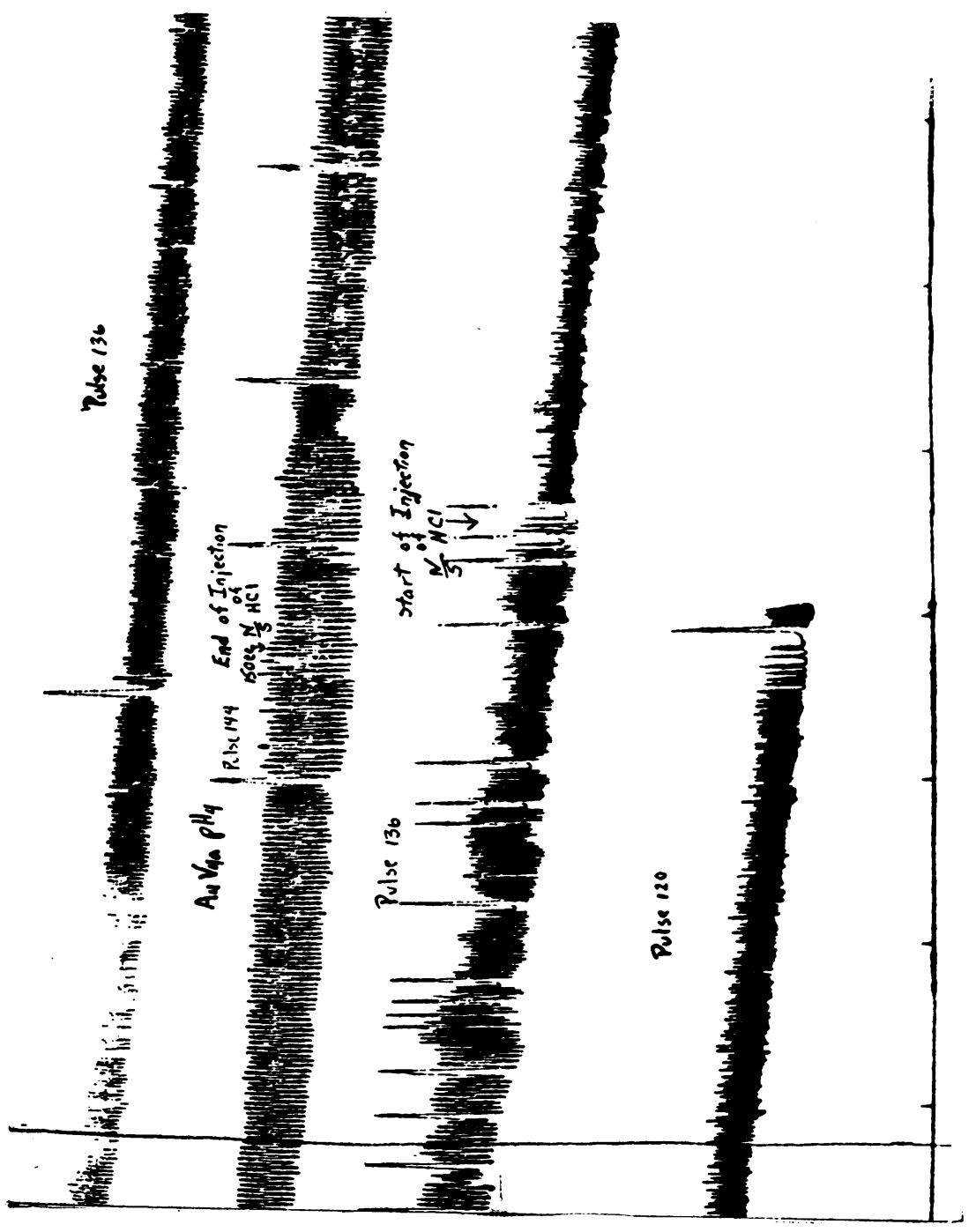

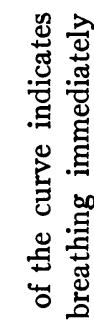

苟㟧

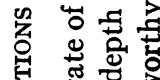

究

㲾

它

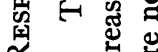

为害焉

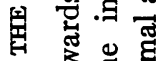

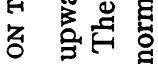

罗

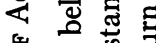

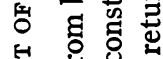

式

包

요

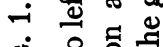

옹요 홍

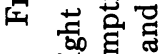

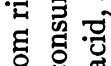

赵

엉동

话

눙.

ปิ

苋

E 总 
liter per minute, in the smaller dogs and two liters per minute in the larger animals.

The effects of acid. (Tables 1, 2, 3, 5, 6, and 7; figures 1,2,3 and 4.) As soon as the injection was made the respirations changed, bęcoming deeper in all instances and more rapid in some animals, slower in others (see fig. 1). Thus hyperpnea rather than polypnea is characteristic of acidosis in the dog as well as in the human being. The minute ventilation was increased in all experiments, the degree of increase varying from 30 to 200 per cent. The effective ventilation was increased to a greater degree than the figures show because the deeper respirations after acid resulted in a smaller percentage of dead space exchange.

A striking feature as one watched the dogs was the similarity in breathing to that seen in diabetic coma and uraemia. These respiratory phenomena simulated closely those described in Walters' (1888) classical experiments.

The effects on the pulse were variable, the rate being sometimes increased and in other instances diminished. The oxygen consumption was not materially changed, though as a rule it was slightly increased. One rather striking feature was the flushing of the gums and tongue. This appeared within two or three minutes after the injection of acid and lasted twenty to thirty minutes. This clinical evidence of vasodilatation is of considerable interest and is referred to later.

The hydrogen ion concentration was uniformly increased, the degree of change varying greatly in different animals. In general the increase was proportional to the amount and the rapidity of the injection of acid.

The blood flow was increased in all instances, the degree of increase tending to parallel the degree of acidosis. As this is the point which we wish particularly to emphasize the average figures for eight experiments in which acid was injected are shown.

\begin{tabular}{l|c|c|c}
\hline & $\mathrm{pH}$ & $\begin{array}{c}\text { Blood flow } \\
\text { per minute }\end{array}$ & Output per beat \\
\cline { 2 - 4 } & & liters & $c_{c .}$ \\
Before injecting acid................ & 7.24 & 1.38 & 22.1 \\
Five to ten minutes after the injection of acid.. & 7.01 & 3.10 & 42.0 \\
Forty-five to ninety minutes after the in- & 7.17 & 2.01 & 30.2 \\
jection.......................... & 7.17 & \\
\hline
\end{tabular}


T. R. HARRISON, C. P. WILSON AND A. BLALOCK
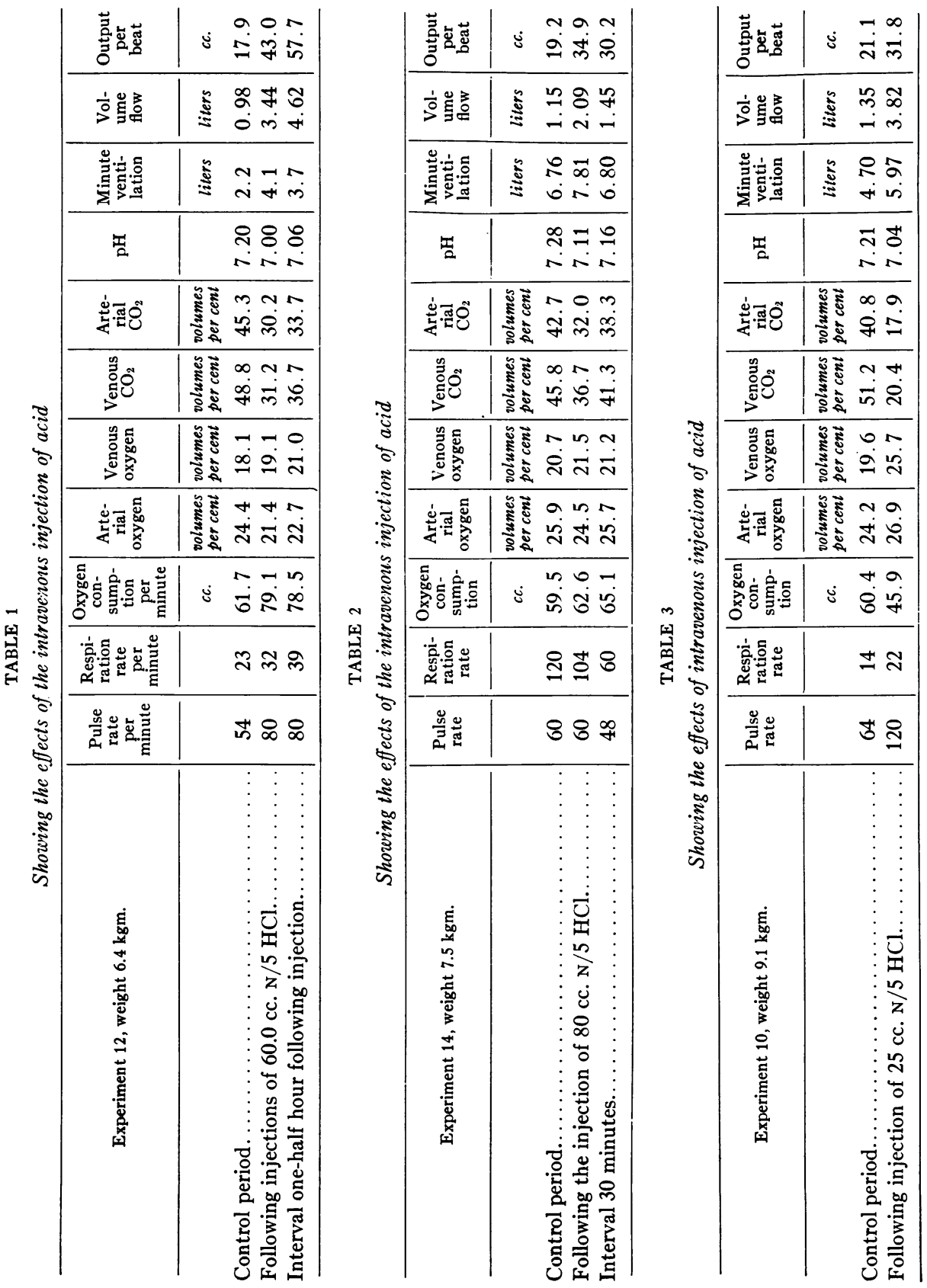


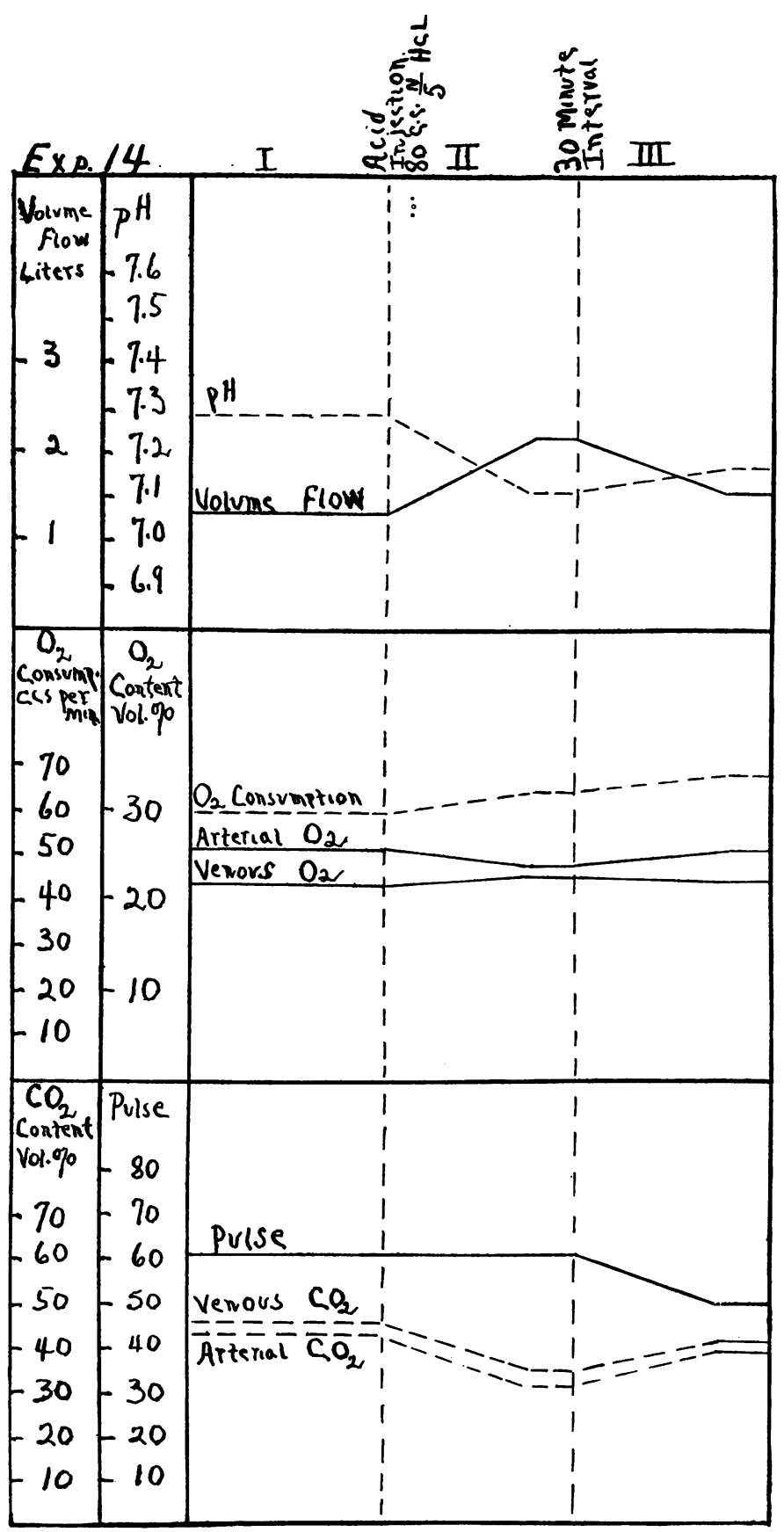

Fig. 2. The Effect of AcID

This chart illustrates a typical experiment. Following the injection of acid the $\mathrm{pH}$ changed from 7.28 to 7.11 and the blood flow increased from 1.1 to 2.0 liters. The arterial and venous oxygen contents approached each other; the blood $\mathrm{CO}_{2}$ content decreased. The pulse rate and oxygen consumption remained relatively constant. After 30 minutes the various functions approached normal.

In this and the following charts time relations are neglected. The various functions are drawn as if constant at the time of puncture. The drawings are purely schematic. 


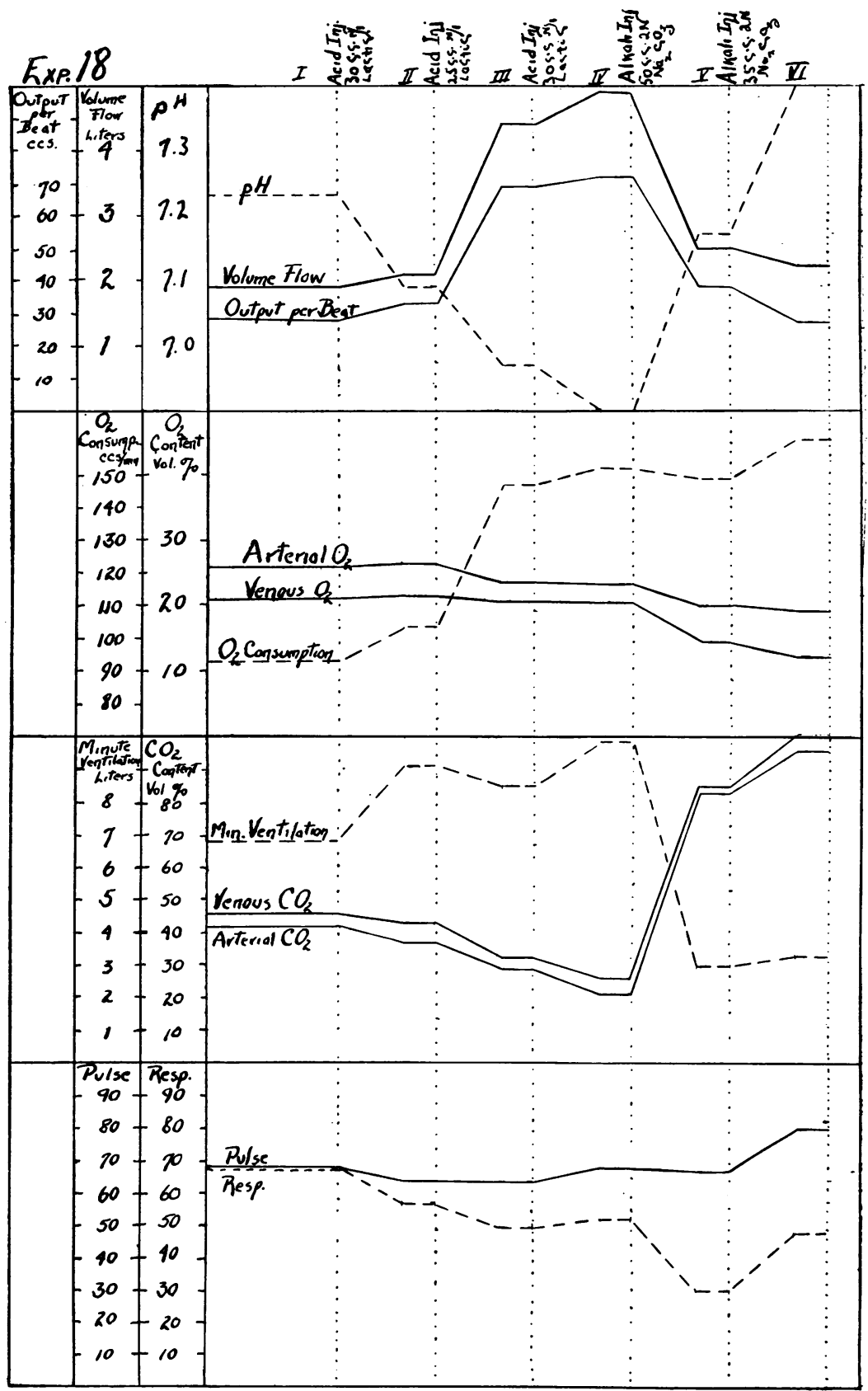

Fig. 3. The Effect of Repeated Injections of Acm and Alkali

In this experiment the animal became restless and the oxygen consumption steadily increased. This probably explains the fact that even with alkalosis the blood flow was not less than in the control period. However the increasing blood flow with increasing $\mathrm{H}$-ion concentration and decreasing blood flow with alkalosis were quite striking. The rise in minute ventilation and drop in blood $\mathrm{CO}_{2}$ content with acid, and the reversed effects with alkali are noteworthy. 
When acid was injected the blood flow was increased more than 100 per cent, and this increase was due to an increase in the output per beat rather than an augmentation of the pulse rate. After an interval of thirty to sixty minutes the acidosis diminished and the blood flow and output decreased.

The carbon dioxide content of the blood was, as would be expected, much decreased after the injection of acid, the figures varying between 10 and 30 volumes per cent. This fall was dependent on overventilation and was a compensatory mechanism similar to the changes in diabetic and renal acidosis.

The effects of alkali. (Tables 4, 5, 6, and 7; figs. 3, 4, 5 and 6.) Almost immediately after the injection of $50 \mathrm{cc}$. of $\mathrm{N} / 1 \mathrm{Na}_{2} \mathrm{CO}_{3}$ the respirations became very shallow and in many instances apnea occurred (fig. 6). In only one animal was the apnea fatal. The animals did not become flushed but in several instances cyanosis was noted. The pulse rate usually increased by ten to thirty beats per minute. The oxygen consumption and arterial oxygen were not much affected, while the venous oxygen became distinctly lower. A very marked rise in both arterial and venous $\mathrm{CO}_{2}$ occurred. The $\mathrm{H}$-ion concentration diminished, the blood flow and output per beat decreased. The average figures for four experiments were as follows:

\begin{tabular}{|c|c|c|c|}
\hline & $\mathrm{pH}$ & $\begin{array}{l}\text { Blood flow } \\
\text { per minute }\end{array}$ & Output per beat \\
\hline & & liters & $c c$. \\
\hline Before injection $\ldots \ldots \ldots \ldots \ldots \ldots \ldots \ldots$ & 7.26 & 1.54 & 23.2 \\
\hline 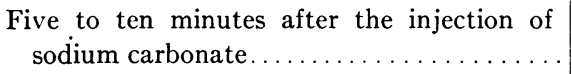 & $7.60+$ & 1.31 & 19.3 \\
\hline Forty-five to ninety minutes later $\ldots \ldots \ldots \ldots$ & $7.60+$ & 1.19 & 14.5 \\
\hline
\end{tabular}

It is to be noted that the $\mathrm{H}$-ion concentration of the blood shows little tendency to return to normal. This is in contrast to the experiments with acid, and in which the $\mathrm{pH}$ values were approaching normal an hour after the injection. The difference is explained by the fact that the body can excrete acid by the lung as well as by the kidneys,

Fig. 4. The Effect of Alkali AND Acm

The usual effects of alkalosis; i.e., diminished volume flow, increased $\mathrm{CO}_{2}$ content are followed by changes in the reverse direction when acid is injected. 


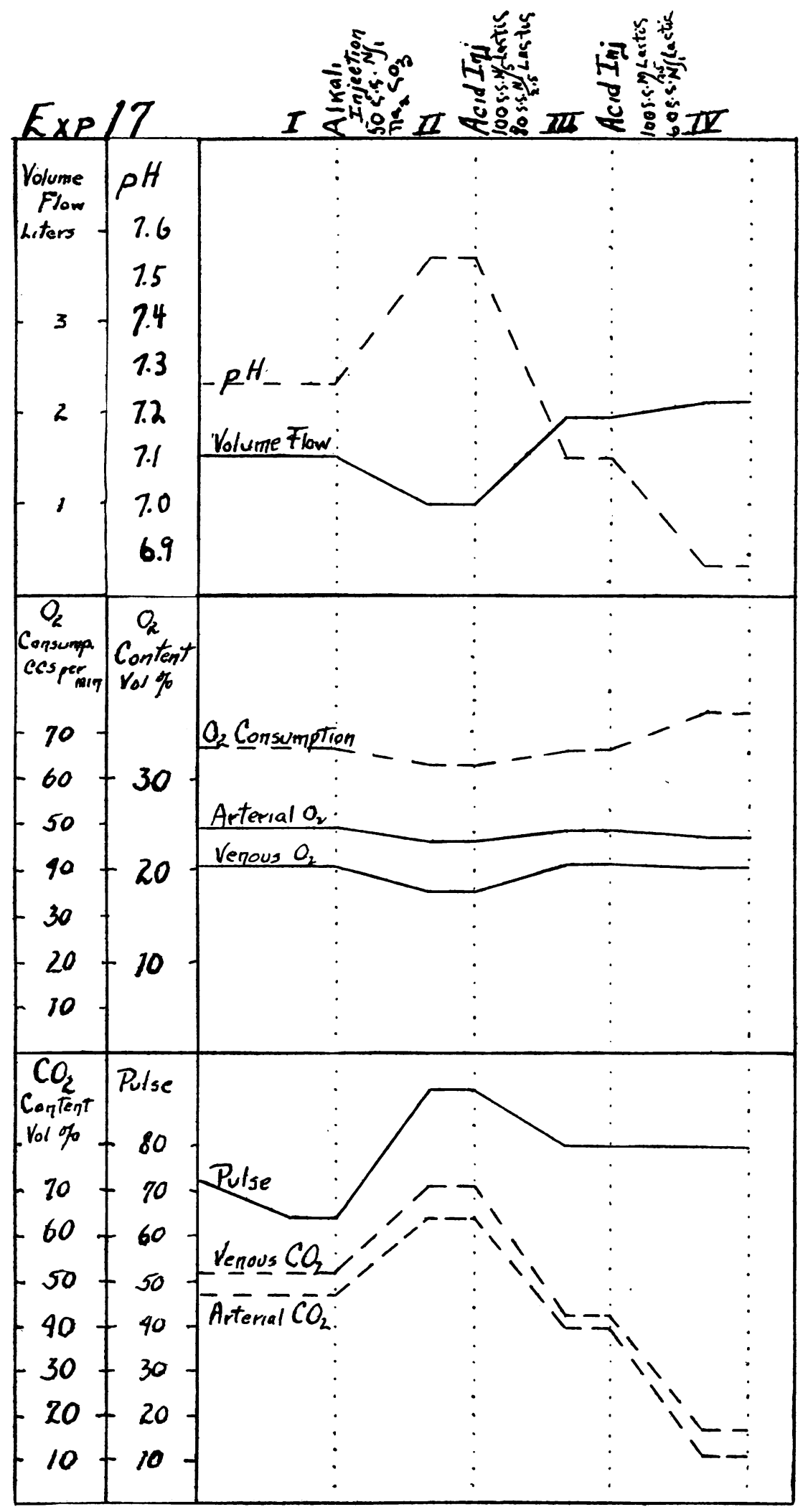

FIG. 4 


\begin{tabular}{|c|c|c|c|}
\hline 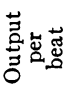 & ني & $\begin{array}{l}\sim \\
a \\
a\end{array}$ & $\stackrel{n=}{=}$ \\
\hline 官萝言 & $\stackrel{\Xi}{\Xi}$ & $\begin{array}{l}\because 28 \\
=\mathrm{g}\end{array}$ & $\begin{array}{ll}2 & \infty \\
0 & 0\end{array}$ \\
\hline 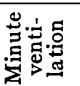 & 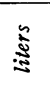 & $\begin{array}{l}\stackrel{\vec{N}}{\propto} \infty \\
\dot{0} \sim\end{array}$ & $\begin{array}{l}n \mathbb{N} \\
m i n\end{array}$ \\
\hline 窝 & & $\stackrel{\substack{0 \\
\sim}}{\sim}$ & $\begin{array}{l}+ \\
\text { So } \\
0\end{array}$ \\
\hline 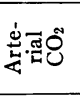 & है & 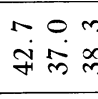 & $\dot{a}$ \\
\hline 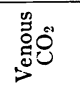 & है: & $\begin{array}{l}\infty \hat{m} \\
\dot{f} \vec{m}=\end{array}$ & $\begin{array}{l}n \rightarrow a \\
\dot{0} \\
\infty\end{array}$ \\
\hline 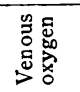 & है & 穴依 & $\begin{array}{l}0.9 \\
0 \\
0\end{array}$ \\
\hline 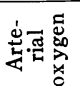 & है: & 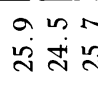 & $\vec{~}$ \\
\hline 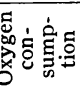 & ن & $\begin{array}{l}\text { no } \\
\text { iñ }\end{array}$ & $\begin{array}{l}\overrightarrow{0} 0 \\
\text { in }\end{array}$ \\
\hline 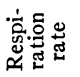 & & తి & Nㅗㅇㅏ \\
\hline 总苛 & & 88 & 용 \\
\hline 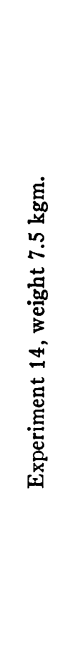 & & 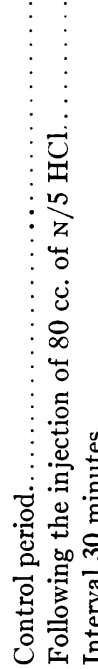 & 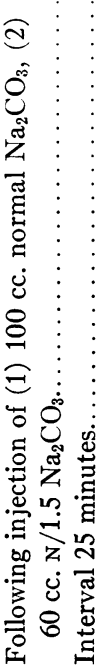 \\
\hline
\end{tabular}




\begin{tabular}{|c|c|c|c|c|c|}
\hline & 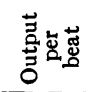 & ن & $\begin{array}{l}0 \ddot{1} \\
\ddot{\sim} \cong\end{array}$ & $\stackrel{+}{\stackrel{+}{N}}$ & $\grave{i}$ \\
\hline & 穴芳言 & 离 & 战 & $\stackrel{n}{\alpha}$ & $\vec{i}$ \\
\hline & 究 & & ํำ & $\stackrel{ }{ }$ & $\begin{array}{l}1 \\
8 \\
0\end{array}$ \\
\hline 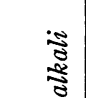 & 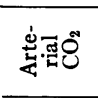 & 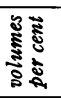 & 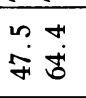 & $\ddot{q}$ & $\stackrel{m}{=}$ \\
\hline $\begin{array}{l}5 \\
5 \\
.05\end{array}$ & 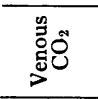 & 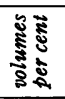 & ஸ̊ & $\begin{array}{l}\infty \\
\stackrel{\sim}{f}\end{array}$ & 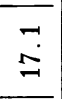 \\
\hline 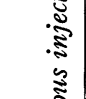 & 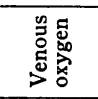 & 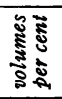 & & $\dot{\hat{\imath}}$ & 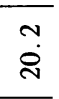 \\
\hline 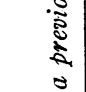 & 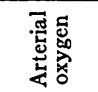 & 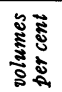 & ฟָ & $\stackrel{m}{\sim}$ & $\hat{\sim}$ \\
\hline 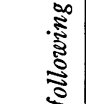 & 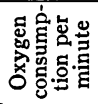 & ن́ & $\ddot{8}$ & $\ddot{0}$ & 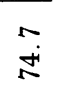 \\
\hline $\begin{array}{ll}\mathbb{Z} \\
0\end{array}$ & 总 苛 & & ఈั สั & ஓ & \& \\
\hline 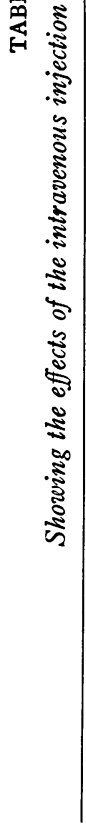 & 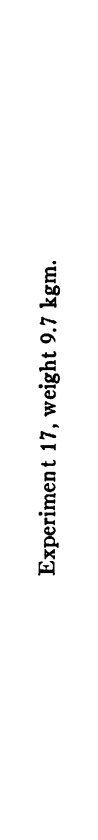 & & $\begin{array}{c}\vdots \\
\vdots \\
\vdots \\
\vdots \\
\vdots \\
\vdots \\
\vdots \\
\vdots \\
\vdots \\
\vdots \\
\vdots \\
\vdots \\
\vdots \\
\vdots \\
\vdots \\
\vdots \\
\vdots \\
\vdots \\
\vdots \\
\vdots \\
\vdots \\
\vdots \\
\vdots \\
\vdots \\
\vdots \\
\vdots\end{array}$ & 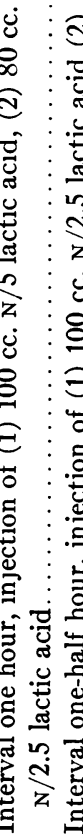 & 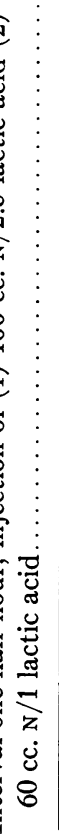 \\
\hline
\end{tabular}

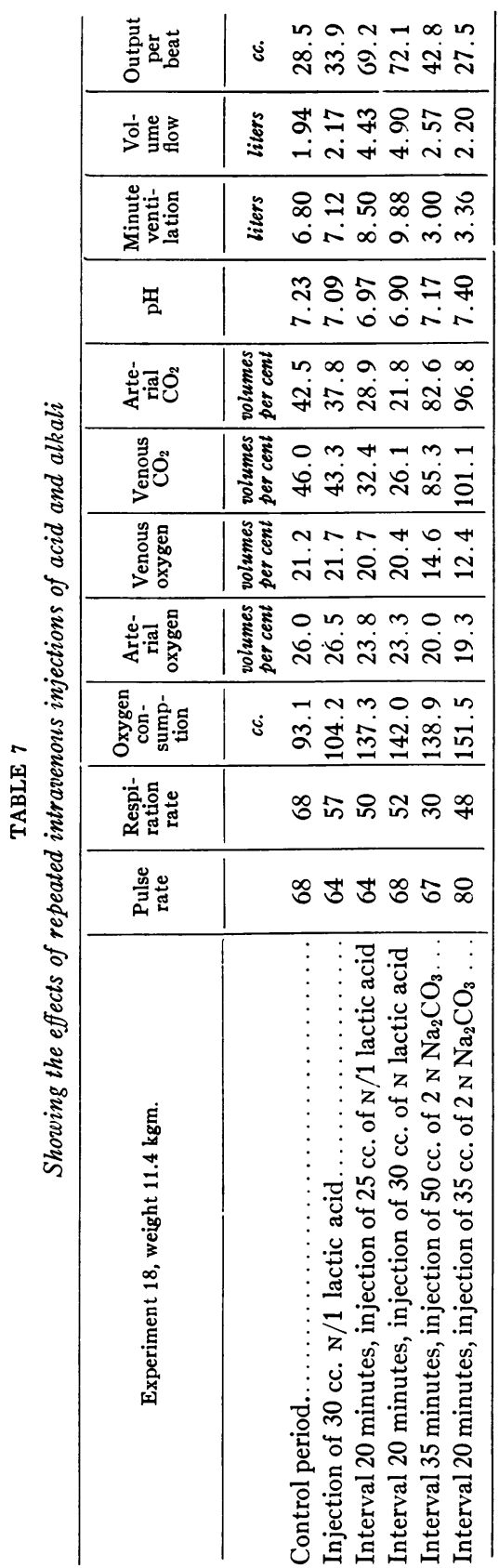




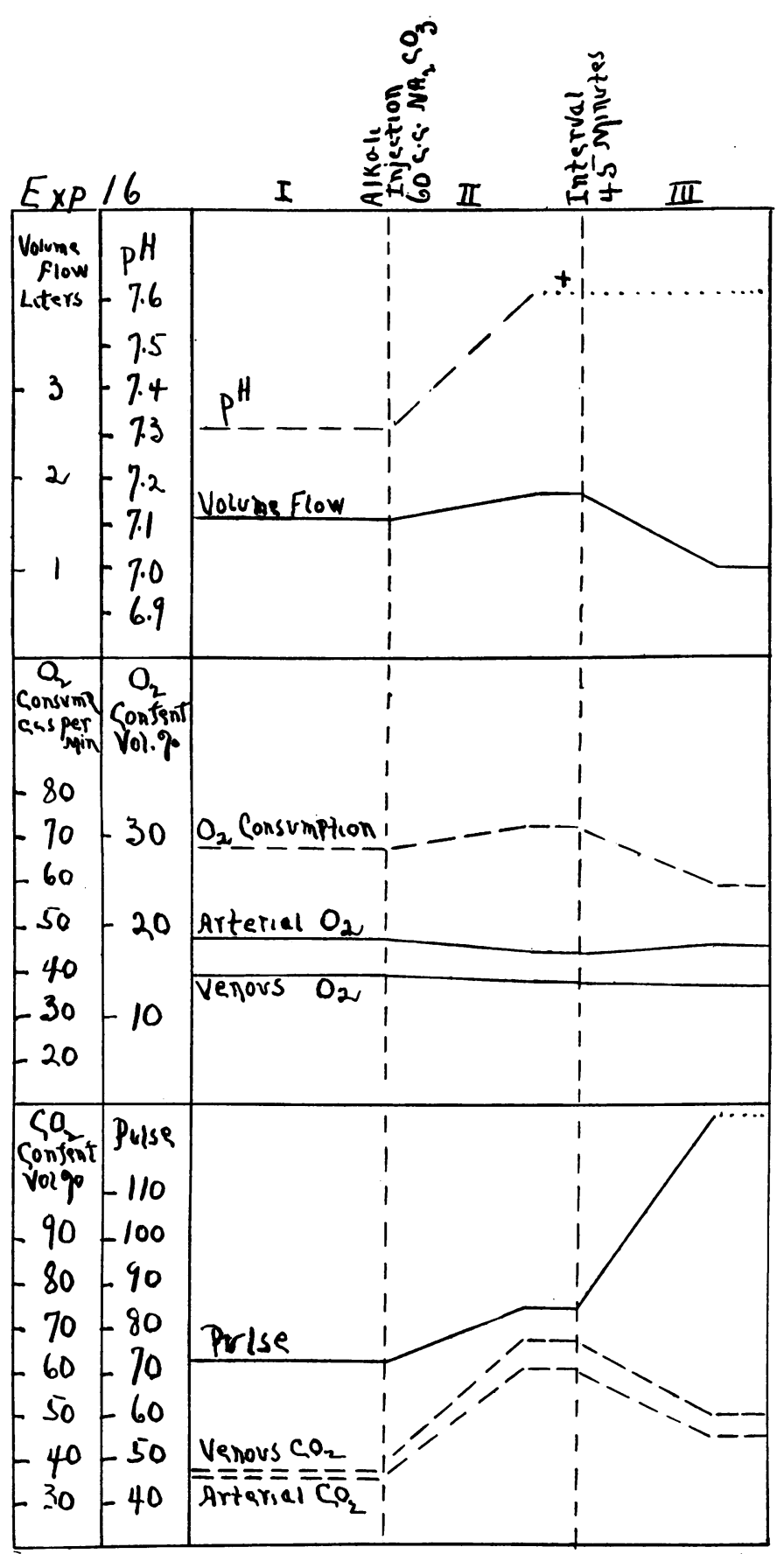

Fig. 5. The Effects of Alkali

In this experiment alkali caused a slight initial rise in the blood flow, followed by a marked fall. The cause of the initial increase is not clear. The oxygen consumption was not changed. The pulse rate increased as the blood flow diminished. The usual elevation in $\mathrm{CO}_{2}$ was found. A comparison of this drawing with figure 2 brings out the fact that the effects of alkali are more lasting than those of acid. This is discussed in the text. 
T. R. HARRISON, C. P. WILSON AND A. BLALOCK
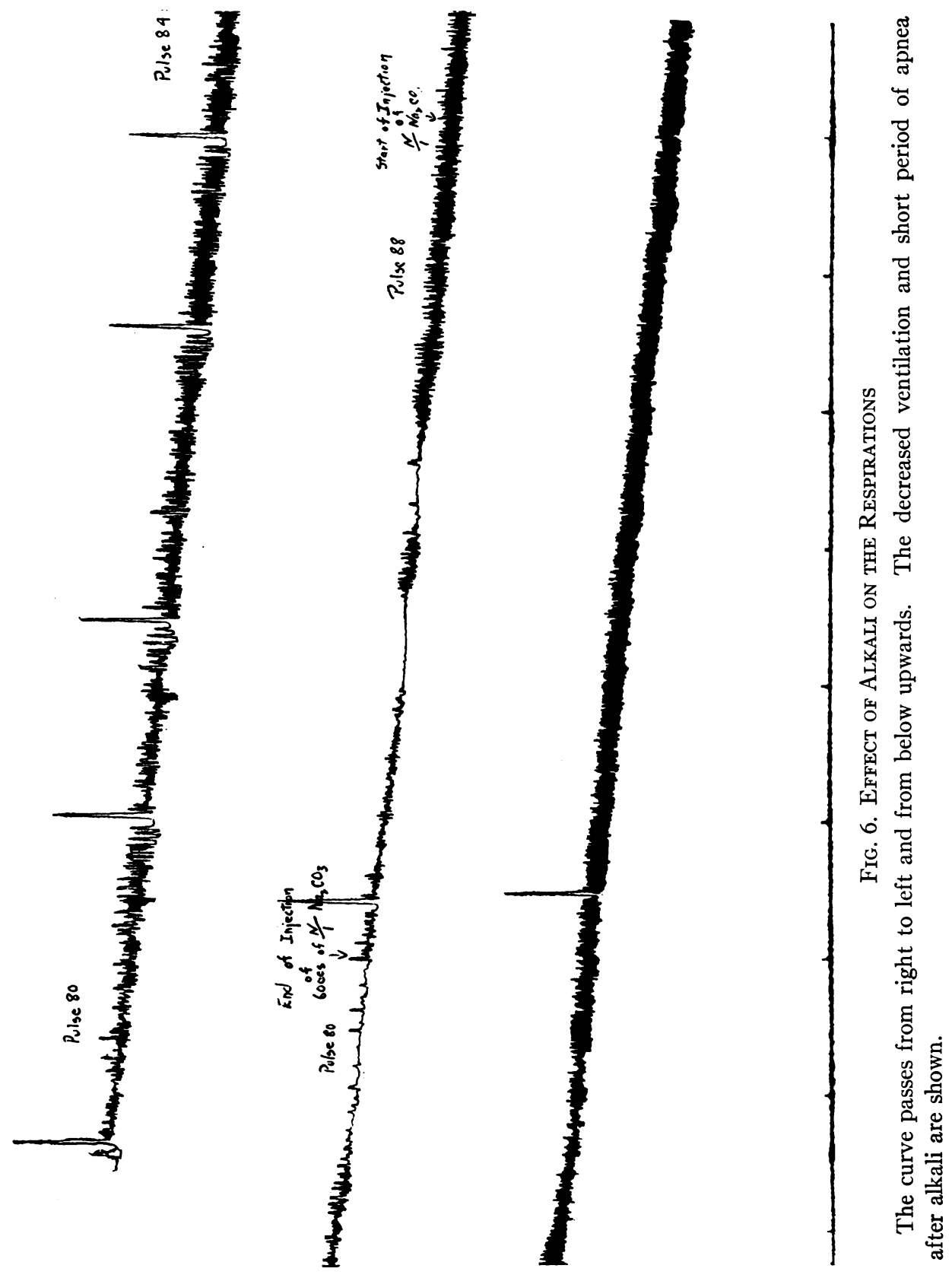


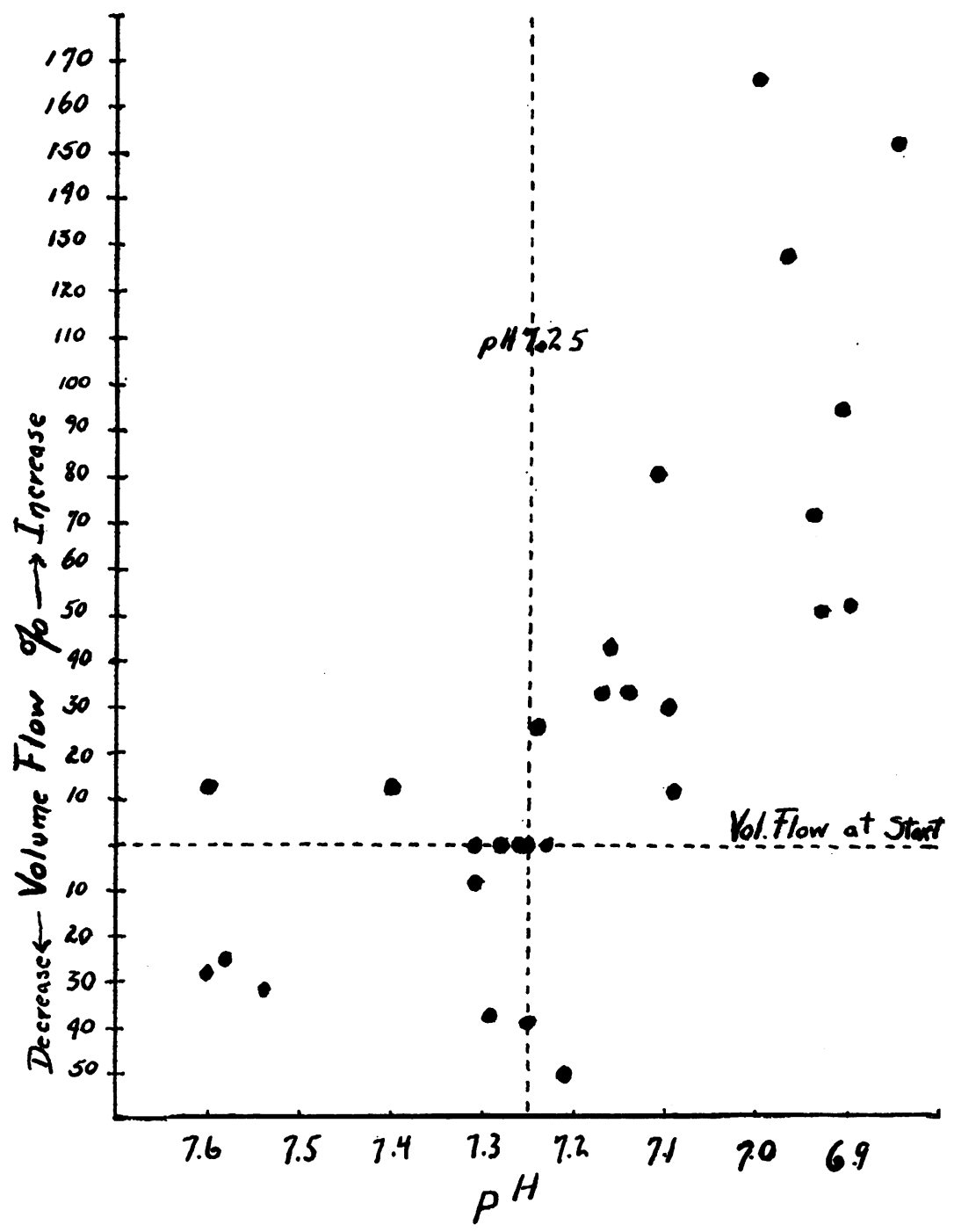

Fig. 7. Relationship of Circulatory Minute Volume to Hydrogen Ion CONCENTRATION

Nearly all the dots to the left (alkaline side) of the normal pH line fall below the normal volume flow line, whereas the points on the right (acid) side are above the normal volume flow level. 


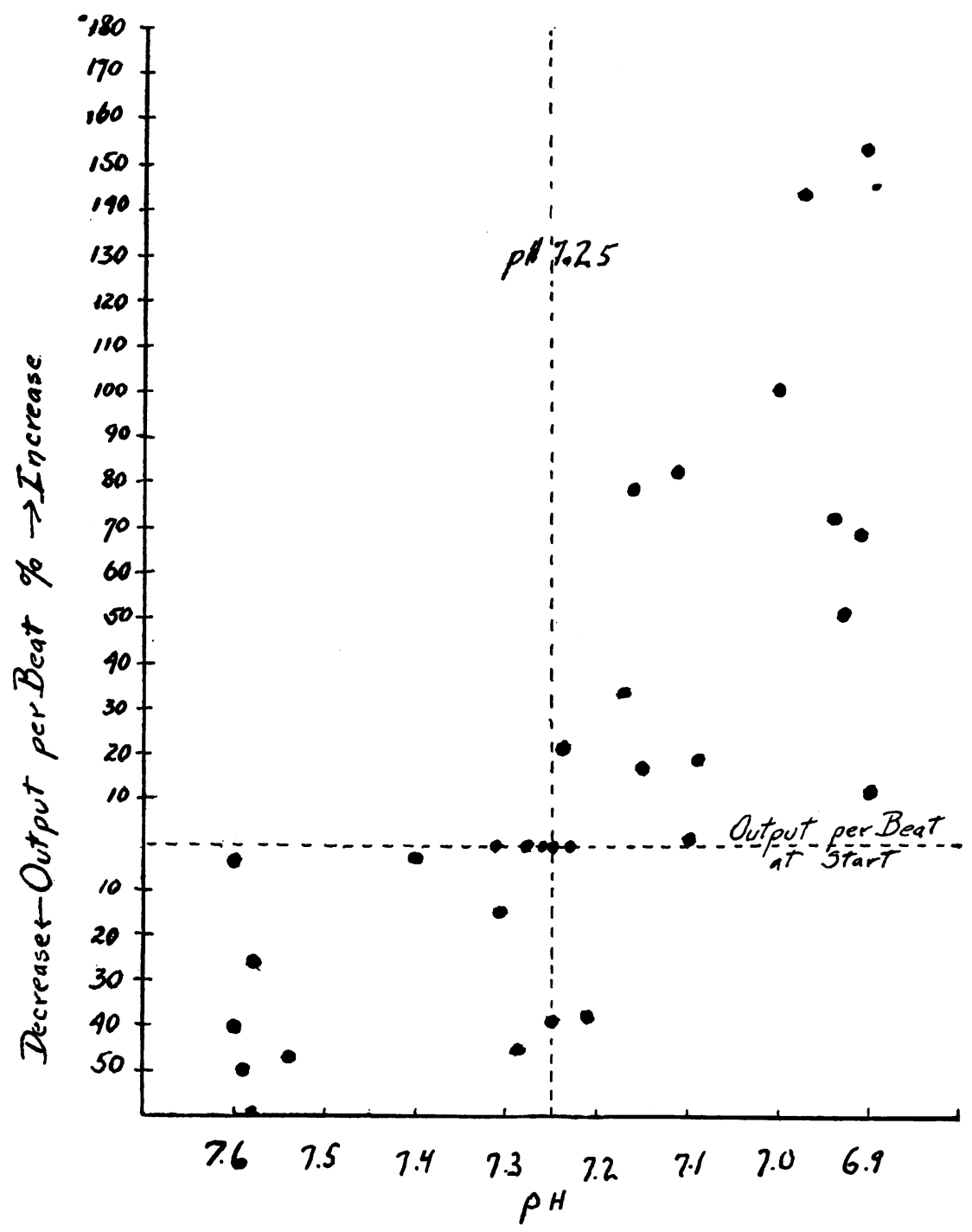

Fig. 8. Relationship of Output per Beat to Hydrogen Ion Concentration

The similarity to figure 5 brings out the point that the changes in volume flow resulting from changes in reaction, are due chiefly to variations in output per beat rather than in pulse rate. 
whereas excess alkali can only be excreted through the kidney. The blood flow became smaller and the output per beat diminished as the duration of the alkalosis increased. The more alkaline values for $\mathrm{pH}$ are denoted by $7.60+$ because colorimetric readings with the Sörensen phenol red standards are unsatisfactory for dog's blood above this $\mathrm{pH}$ value.

In one experiment $40 \mathrm{cc} . \mathrm{N} / 10$ sodium hydroxide was substituted for the usual sodium carbonate. The results were rather surprising. The breathing became at first slow and shallow but soon rapid and deep respirations were noted. At this point the pulse rate was 150 . Blood samples were drawn and the animal was found to have an extreme acidosis $(\mathrm{pH} 6.90-)$, with a greatly diminished blood flow. A few minutes later death occurred-apparently from shock. This apparent paradox, the production of an acidosis by the injection of a strong alkali has been observed by others (McCallum, 1925) and can, we believe, be explained by the assumption that the caustic caused marked tissue destruction. The results of this atypical experiment are not included in the tables.

In figures 7 and 8 , to which the reader's attention is especially directed, the results of our previous experiments on the acidosis produced by respiratory obstruction, are included as well as the changes in $\mathrm{H}$-ion concentration found in the present series of experiments. In figure 7 the volume flow per minute is charted against the $\mathrm{pH}$. It can be seen that acidosis, whether due to respiratory obstruction and hence associated with a high $\mathrm{CO}_{2}$ tension, or whether due to acid injections and thus associated with low $\mathrm{CO}_{2}$ tension, causes an increased blood flow (in the morphinized $\mathrm{dog}$ ) whereas alkalosis is accompanied by a decreased flow. Figure 8 brings out the point that the changes in blood flow are due to variations in cardiac output and not to alterations in heart rate. 


\section{DISCUSSION $^{1}$}

\section{The relationship of hydrogen ion concentration to blood flow}

Boothby (1915) first suggested that the $\mathrm{H}$-ion concentration regulated blood flow. Douglas and Haldane (1922) have reached the same conclusion from the result of studies on man. Means (1924) in his recent monograph pointed out that this suggestion seems likely but, is, as yet, unproved. Henderson $(1908,1923)$ has repeatedly emphasized the importance of $\mathrm{CO}_{2}$ as a regulator of venous inflow and cardiac output.

In our experiments acidosis was associated with an increased circulatory minute volume, and alkalosis with a decreased blood flow (figs. 7 and 8). It is of importance to know whether the change in volume flow is a result of the change in reaction or simply a concomitant phenomenon.

Part of the rise which occurred with acidosis might possibly be explained by the increased work of breathing. If the effect on volume flow were due entirely to the elevated metabolism of increased work a parallelism between blood flow and oxygen consumption should occur. No such parallelism was observed, for the oxygen consumption did not increase in as great a degree as did the blood flow. With alkalosis a conspicuous decrease in oxygen consumption occurred in only one instance whereas the blood flow was diminished in most instances. The exceptions to this were noted in the animals in which an elevated oxygen consumption occurred.

It might be said that the changes found, if not due to changes in work, were due to the mechanical effects of changes in the depth of respiratory movements with consequent variations in venous inflow.

1 The literature on the subject of circulatory minute volume is extensive and is discussed in some detail in Henderson's (1923) recent review. Only such work as bears more or less directly on the relationship of H-ion concentration to blood flow will be noted here.

Most of the work previously done has been concerned with the effect of $\mathrm{CO}_{2}$ tension rather than the $\mathrm{H}$-ion concentration, and has been done on animals anaesthetized with ether or urethane, both of which may very possibly modify the circulatory mechanism. Much of the work has been done on the isolated heart-lung preparation. Caution must be used in applying the result to the normal circulation. 
This explanation does not hold in view of the work of Henderson (1908) who showed nearly 20 years ago that the mechanical factors are less important than the chemical factors. Furthermore, Marshall (1925) has found that the blood flow of the normal dog is no greater in summer than in winter, although the minute ventilations may be doubled because of panting.

Since therefore the changes in volume flow observed in these experiments cannot be explained on the basis of changes in metabolism or changes in the mechanism of respiration, we feel justified in stating that the variations observed in blood flow were due to the variations produced in $\mathrm{H}$-ion concentration.

Eppinger (1924) has recently reported a great increase in circulatory minute volume during attacks of "cardiac asthma." Lewis and his associates (1913) observed acidosis during such attacks.

Patterson (1915), using the heart-lung preparation, found that high $\mathrm{CO}_{2}$ tension caused a diminished blood flow. The addition of adrenalin, however, to the perfusion fluid caused an increase. Adrenalin and $\mathrm{CO}_{2}$ caused a greater increase than did adrenalin alone. Cannon and Corrasco-Formiguera (1922) noted that the secretion of adrenalin was augmented by asphyxia. Thus one might expect an increased blood flow at a high $\mathrm{CO}_{2}$ tension.

Schneider and Truesdell (1922) found an increased flow through the hand when carbon dioxide in as high a concentration as 3 per cent was present in the inspired air. At higher concentrations the flow was diminished. Douglas and Haldane (1922) observed no increase in the circulatory minute volume when an excess of $\mathrm{CO}_{2}$ was breathed. They believed that no change in $\mathrm{H}$-ion concentration was produced under the conditions of the experiments. Henderson and Harvey (1918) believe that a great increase in the circulation rate occurs when the ' $\mathrm{CO}_{2}$ tension of the blood becomes excessive.

Henderson (1923) emphasizes the importance of $\mathrm{CO}_{2}$ as a hormone regulating venous pressure, and hence the diastolic filling and circulatory minute volume. He points out that this effect of carbon dioxide may possibly be specific or may result from the increased $\mathrm{H}$-ion concentration due to the $\mathrm{CO}_{2}$. The latter hypothesis would seem to be the correct one in view of the above experiments. Two different types of acidosis were produced, the one associated with a high $\mathrm{CO}_{2}$ 
tension of the blood, the other with a low $\mathrm{CO}_{2}$ tension. In both conditions the volume flow was increased. Since the results were the same whether the acid was carbonic, hydrochloric or lactic, there is little doubt but that the increase in blood flow was due to the increased hydrogen ion concentration of the blood.

Other observers (Henderson (1908), Douglas and Haldane (1922)), observed a decrease in blood flow with excessive artificial respiration, which as Grant and Goldman (1922) showed causes alkalosis. Under such conditions alkalosis is associated with a diminished $\mathrm{CO}_{2}$ tension of the blood. In our experiments alkalosis was produced by the injection of alkali and was associated with a high $\mathrm{CO}_{2}$ tension of the blood, but a decreased blood flow. Here again we are led to the conclusion that the changes in blood flow are determined by changes in the hydrogen ion concentration and not by variations in the carbon dioxide content of the blood.

It is of some interest to speculate briefly on the mechanism through which the $\mathrm{pH}$ influences the blood flow. The work of Fleisch (1921) who found that acid caused a peripheral dilitation and an increased capillary flow is of interest in this connection. Other factors remaining constant, capillary dilatation will, if not extreme, cause a more rapid return of blood to the veins, increased rate of venous flow and greater diastolic filling of the heart. It seems probable that this is the mechanism through which the $\mathrm{H}$-ion concentration modifies the blood flow. Henderson (1923) expresses a similar idea when he discusses the importance of $\mathrm{CO}_{2}$ in the regulation of venous pressure. Eppinger (1924) has evidence that the great increase in blood flow during attacks of "cardiac asthma" is due to diminished peripheral resistance. Harrison, Dock and Holman (1924) found an elevated blood flow in dogs with arteriovenous fistulae. This was probably dependent on diminished peripheral resistance.

\section{The relationship of blood flow to output per beat}

One of the most striking results of the experiments was the finding of a 100 to 200 percentage increase in blood flow with no significant increase in pulse rate. This is contrary to Henderson's (1923) view, but is in accord with the finding of numerous other workers (Marshall (1925), Eppinger (1924), Zuntz and Hagemann (1898), Plesch (1909), 
Krogh and Lindbard (1912) and others). In our experiments the pulse rate has usually paralled the oxygen consumption more closely than the blood flow. It is well known that the minute respiratory volume is controlled by two factors, the nervous factor and the chemical factor. It is possible that the circulatory minute volume is similarly controlled.

We have concluded from these experiments that the H-ion concentration constitutes the most important if not the sole regulatory mechanism of the circulation of the morphinized dog. There is considerable evidence to indicate that this is also true in man. However this evidence is by no means conclusive. If sufficiently accurate methods are available this problem will be studied in the future. At the present time no definite conclusions as to the circulation of man can be drawn from this work.

\section{SUMMARY AND CONCLUSIONS}

The effects of acidosis and alkalosis in dogs have been studied with special reference to the blood flow. Acidosis was produced (1) by obstruction to the respirations, (2) by the injection of hydrochloric and lactic acid. Alkalosis was produced by the administration of sodium carbonate. The changes in pulse rate, respiratory rate, minute ventilation, oxygen consumption, arterial oxygen, venous oxygen, arterial $\mathrm{CO}_{2}$, venous $\mathrm{CO}_{2}$, internal respiratory quotient, hydrogen ion concentration, circulatory minute volume and cardiac output per beat have been observed. The following statements are believed to be true for the morphinized dog.

1. An increase in the hydrogen ion eoncentration of the blood causes an increased blood flow.

2. A decrease in hydrogen ion concentration causes a decreased blood flow.

3. These effects occur regardless of the $\mathrm{CO}_{2}$ tension of the blood.

4. Changes in the hydrogen ion concentration have no constant effect upon the oxygen consumption or the pulse rate.

5. The cardiac output per beat is much affected by the hydrogen ion concentration, being greater than normal in acidosis and less than normal in alkalosis. 
6. The changes in respiratory rate are variable. When the respirations are unimpeded, intravenous injections of acid always cause increased respiratory depth and increased minute ventilation, and alkali usually causes diminished respiratory depth and diminished minute ventilation.

It is suggested that these results may be applicable to man.

It is a pleasure to acknowledge our indebtedness and express our appreciation to Dr. E. K. Marshall, Jr., and Dr. G. A. Harrop for encouragement and many helpful suggestions in regard to this work.

\section{BIBLIOGRAPHY}

Barcroft, J., Boycott, A. E., Dunn, J. S., and Peters, R. A.: Quart. Jour. Med., 1919-1920, xiii, 35. Observations on the Respiration and Circulation in the Goat.

Blalock, A., Harrison, T. R., and Wilson, C. P.: Arch of Surg. (in press). The Effect of Respiratory Obstruction on the Respiration and Circulation of Morphinized Dogs.

Boothby, W. M.: Amer. Jour. Phys., 1915, xxxvii, 383. A Determination of the Circulation Rate in Man at Rest and at Work.

Cannon, W. B., and Corrasco-Formiguera, R.: Amer. Jour. Phys., 1922, lxi, 215. Studies on Conditions of Activity in Endocrine Glands. XI. Further Evidence of Reflex and Asphyxial Secretion of Adrenin.

Cullen, G. E.: Jour. Biol. Chem., 1922, lii, 501. Studies in Acidosis. xix. The Colorimetric Determination of the Hydrogen Ion Concentration of the Blood Plasma.

Douglas, G. G., and Haldane, J. S.: Jour. Phys., 1922, lvi, 69. The Regulation of General Circulation Rate in Man.

Eppinger, H.: Das Asthma Cardiole. Berlin, 1924.

Fleisch, A.: Zeit. f. Allg. Physiol., 1921, xix, 269. Die Wasserstoffioninkonzentration als Peripher Regulatorisches Agens der Blutversorgung.

Grant, S. B., and Goldman, A.: Amer. Jour. Phys., lii, 209. A study of Forced Respiration: Experimental Production of Tetany.

Harrison, T. R., Dock, W., Holman, E.: Heart, 1924, xi, 337. The Blood Flow in Experimental Arterial Venous Fistula.

Hawkins, J. A.: Jour. Biol. Chem., 1923, lvii, 493. A Micro Method for the Determination of the Hydrogen Ion Concentration of Whole Blood.

Henderson, Y.: Amer. Jour. Phys., 1908, xxi, 126. Acapnia and Shock: I. Carbon Dioxide as a Factor in the Regulation of the heart Rate.

Henderson, Y.: Physiological Reviews, 1923, iii, 165. Volume Changes of the Heart.

Henderson, Y., and Harvey, S. C.: Amer. Jour. Phys., 1918, xlvi, 133. Acapnia and Shock: The Veno-pressor Mechanism. 
Krogh, A., and Lindhardt: Skand. Archiv f. Physiol., 1912, xxvii, 100.

Lewis, T., Ryffel, J. H., Wolf, C. G. L., Cotton, T., and Barcroft, J.: Jour. Physiol., 1913-14, v, 45. Observations Relating to Dyspnoea in Cardiac and Renal Patients.

Marshall, E. K.: 1925. Personal communication.

McCallum, W. G.: 1925. Personal communication.

Means, J. H.: Medicine, 1924, iii, 309. Dyspnoea.

Patterson, A. W.: Proc. Roy. Soc., Series B, 1915, lxxxviii, 371. The Antagonistic Action of Carbon Dioxide and Adrenalin on the Heart.

Schneider, E. C., and Truesdell, D.: Amer. Jour. Phys., 1922-23, lxiii, 155. The Effects on Circulation and Respiration of an Increase in the Carbon Dioxide Content of the Blood in Man.

Walter, F.: Archiv. f. Exp. Path. u. Phar., 1877, vii, 148.

Zuntz and Hagemann: Landwirtsch Jahrbucher, 1898, Suppl. III, 371. 